\title{
Workplace violence among healthcare workers during COVID-19 pandemic in a Jordanian governmental hospital: the tip of the iceberg
}

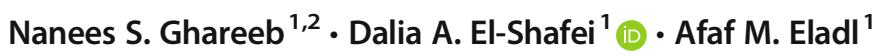 \\ Received: 19 April 2021 / Accepted: 21 June 2021 / Published online: 26 June 2021 \\ (C) The Author(s), under exclusive licence to Springer-Verlag GmbH Germany, part of Springer Nature 2021
}

\begin{abstract}
During the COVID-19 pandemic, significant cases of violence, intimidation, or stigmatization were targeted at healthcare workers (HCWs), patients, and medical infrastructure. These occurrences were most likely just the "tip of the iceberg," with much more remaining unnoticed. The present study's purpose was to assess the frequency, characteristics, effects, and contributing factors of workplace violence (WPV) committed against HCWs in AlKarak Governmental Hospital (KGH), South Jordan, during the COVID-19 pandemic. A cross-sectional study was conducted among 382 HCWs (170 physicians and 212 nurses) working in the KGH, Jordan, during January and February 2021, using a semi-structured questionnaire. The current study showed that most participants $(65.5 \%)$ reported exposure to WPV, mainly verbal violence $(52.0 \%)$, and patients' relatives were the principal perpetrators in most incidents. The regular reporting of these incidents is deficient. The victims suffered psychological and physical effects. These assaults on healthcare facilities highlight the importance of effective risk communication at all levels of society to minimize anxiety, stigma, and, eventually, WPV. The way we communicate about COVID-19 is vital in motivating people to take proactive steps to fight the disease and safeguard healthcare.
\end{abstract}

Keywords Workplace violence $\cdot$ Healthcare workers $\cdot$ Front lines $\cdot$ Governmental hospital $\cdot$ COVID-19 pandemic $\cdot$ Jordan

\section{Introduction}

The coronavirus pandemic is a global pandemic of coronavirus disease 2019 (COVID-19) (Sharma et al. 2020) that was discovered in Wuhan, China, for the first time, then spread all over the globe (Neto et al. 2020).

Healthcare workers (HCWs) are the backbone of all healthcare systems. Therefore, they are at the front line of COVID-19 and confront threats that endanger their lives (Rodríguez-Bolaños et al. 2020).

Workplace violence (WPV) is described as the use of force against another person or a group of people in work-related

Responsible Editor: Lotfi Aleya

Dalia A. El-Shafei

d_elshaf3y_mony@hotmail.com

1 Department of Community, Environmental and Occupational Medicine, Faculty of Medicine, Zagazig University, Zagazig, Egypt

2 Department of Public Health, Faculty of Medicine, Mutah University, Mu'tah, Jordan situations that result in physical or psychological damage, and even death (Ferri et al. 2016). WPV among HCWs is recognized as an alarming global phenomenon (Yenealem et al. 2019). According to the World Health Organization (WHO), about $8 \%$ to $38 \%$ of HCWs are exposed to violence, mainly physical violence (Khan et al. 2021), by an incidence of eight attacks per 10,000 employees compared to two per 10,000 for the general workplaces (WHO 2018).

During the COVID-19 pandemic, over 600 cases of violence, intimidation, or stigmatization were targeted at HCWs, patients, and medical infrastructure across 40 countries in Asia, the Americas, Africa, and the Near and Middle East regions as recorded by the International Committee of the Red Cross during the first six months of the pandemic. These occurrences were most likely just the "tip of the iceberg," with much more remaining unnoticed. Accordingly, 13 humanitarian organizations urged governments to establish legislation to safeguard $\mathrm{HCWs}$ from assaults during the COVID-19 pandemic, construct safer working conditions, provide mental health assistance, and combat misinformation (Devi 2020). 
The overwhelming spread of COVID-19 cases has triggered a wave of violence against HCWs. Governments, hospital administrations, and HCWs must affirm "zero tolerance" for WPV. Violence against HCWs is a critical phenomenon, and there is a lack of comprehensive research to handle it. The prevailing global trends and evident research deficiencies encourage the need for studies to understand and prevent WPV against HCWs, predominately in the era of epidemics (Rodríguez-Bolaños et al. 2020).

In Jordan, like other developing countries, WPV in the healthcare sectors is suffering from scanty research studies and lack of documentation, although it has become a significant problem for $\mathrm{HCWs}$, especially in the past decade (ALBashtawy 2013).

The present study's objectives were to assess the frequency, characteristics, effects, and contributing factors of WPV committed against HCWs in AlKarak Governmental Hospital $(\mathrm{KGH})$, South Jordan, during the COVID-19 pandemic.

\section{Materials and methods}

A cross-sectional study was conducted among physicians and nurses working in the AlKarak Governmental Hospital (KGH), Jordan, during January and February 2021.

\section{Study population}

Determination of sample size and sampling technique All physicians and nurses working in $\mathrm{KGH}$ were included in the study; they include 240 physicians and 322 nurses, and the response rate was $75.5 \%$. So, the final number of workers who accepted to participate in the study was 424 workers (190 physicians and 234 nurses). The participants were selected from various departments and during varied shifts with the assistance of the departments' managers. We excluded $10 \%$ of participants who were included in the pilot study, so the final number of staff will be 382 (170 physicians and 212 nurses). Since the study was implemented during the COVID-19 pandemic, the authors made considerable precaution to counter face-to-face interaction as applicable. Therefore, the data were collected online through the $\mathrm{KGH}$ staff's online workgroups on "WhatsApp." The authors coordinated with these groups' admins to share the online questionnaire through these groups. The Google Form App was used to create the questionnaire, which was then posted/ reposted via groups.

Inclusion criteria The inclusion criteria were as follows: HCWs (including physicians and nurses) working in clinical settings during the COVID-19 pandemic, having at least one year of work experience, and who gave their consent to participate in the study.
Exclusion criteria The exclusion criteria were as follows: HCWs suffering from mental illnesses such as depression and incomplete answers of the questionnaire.

\section{Data collection tools}

A semi-structured questionnaire was used depending on previous studies (Fallahi-Khoshknab et al. 2016; Alsaleem et al. 2018; Mishra et al. 2018; Harthi et al. 2020), which consisted of the following " 8 " parts:

Part I: Socio-demographic characteristics and occupational history: age, sex, marital state, education, occupation, years of experience, and rotating shifts

Part II: History of exposure to WPV during the last six months: included questions regarding exposure to WPV during the last six months, type (verbal, physical, or mixed), verbal abuse (was defined as being shouted at, sworn at, humiliated, and threatened with harm), physical abuse (was defined as being hits, kicks, pushes, scratches, or pinches), and the perpetrators (colleagues, patients, and patients' relatives)

Part III: Assessment of the negative effect of abusive behavior: included 4 items assessing the impact on the physical and psychological well-being of participants, work performance, and social life.

Part IV: Reactions to verbal or physical abuse: consisted of 11 items, which were as follows: doing nothing, avoiding the source of violence, trying to defend themselves physically, reporting abuse to the manager, transferring to another position, telling the person to stop, using the medicine for sleeping, looking for counseling, avoiding thinking or talking about the abuse, being super alert, and taking a sick leave.

Part V: Reasons for non-reporting an episode of WPV: consisted of 8 items, which were "Not considered important, No harm intended, Offender apologized, Feel ashamed, Considered not beneficial, Can manage without help, Did not want to be recorded in their professional file, and others."

Part VI: Factors contributing to WPV: consisted of 9 items, which were "Intense workload, High patient expectation, Substance abuse by the patient, Long waiting period, Rejection of demands that cannot be accepted, Sensational reports from media, Lack of communication, Inadequate security, and others."

Part VII: HCWs' opinion regarding WPV: consisted of 8 items, which were "Qualified staff can predict a violent episode, Patients should be responsible for all their behavior, Staff has the right to legal action even when the patient is the abuser, Abused staff are victims due to personal trait, Staff should expect to be abused during work, Staff violated without injury should not report the 
incident, Staff taking legal action is at risk of losing their job, Staff pattern and physical setup of work protect them."

Part VIII: Possible preventive measures to control WPV from participants' points of view: an open-ended question.

The study's tools were translated into Arabic and retranslated through a specialized bilinguistic, and the tools were validated by submitting them to a board of discipline experts to judge tool items with relevance and appropriateness. A reliability test was done using the reliability coefficients, which was high and suitable for scientific purposes (Cronbach's alpha ranged from 0.78 to 0.90 ). A pilot study was conducted on $10 \%$ of staff ( 20 physicians and 22 nurses), and those participants were withdrawn from the study to recognize the barriers and issues that may emerge during data collection. The questionnaire was revised according to the results of the pilot study, and some modifications were done, mainly removing the question evaluating sexual harassment as almost all participants of the pilot study refused to answer it and considered it a sensitive question.

Data management The collected data were computerized and statistically analyzed using the SPSS program (Statistical Package for the Social Sciences) version 19.0. Frequencies and percentages were used to reflect qualitative data. Mean and standard deviation were used to summarize quantitative results. Comparison between categorical variables was done by chi-square test. Stepwise multiple logistic regression analysis was carried out to identify independent determinants while adjusting results by potential confounders with their confidence intervals (CIs) 95\% . A P value $<0.05$ was considered statistically significant.

\section{Results}

A total of 382 staff of KGH had participated in the study. Almost half of them (47.1\%) were in the age group 35-50 years with a mean of $40.24 \pm 11.5$ years and more than half of them were female $(57.6 \%)$ with a bachelor's degree (47.1 $\%$ ); nurses were more prevalent $(55.5 \%)$. Also, most staff (75.9\%) worked less than 10 years, and more than half of them $(57.6 \%)$ worked in rotating work shifts (Table 1$)$.

Regarding the history of exposure to WPV during the last six months, most participants $(65.5 \%)$ reported exposure to WPV, mainly verbal (52.0\%) and mixed violence (32.0\%), respectively. The most prevalent verbal violence types were shouts $(90.5 \%)$ and threats with harm $(58.6 \%)$. Pushes $(91.7 \%)$ and hits $(80.8 \%)$ were the prevalent types of physical violence, respectively. The commonest source of violence was from patient relatives $(88.0 \%)$. Psychological problems were
Table 1 Socio-demographic and occupational characteristics of the studied participants $(\mathrm{N}=382)$

\begin{tabular}{|c|c|c|}
\hline Items & No. & $\%$ \\
\hline \multicolumn{3}{|l|}{ Age } \\
\hline $20-35$ & 135 & 35.34 \\
\hline $35-50$ & 180 & 47.12 \\
\hline$>50$ & 67 & 17.54 \\
\hline \multicolumn{3}{|l|}{ Mean \pm SD: $40.24 \pm 11.5$} \\
\hline \multicolumn{3}{|l|}{ Range (years): 22-55 } \\
\hline \multicolumn{3}{|l|}{ Sex } \\
\hline Male & 162 & 42.40 \\
\hline Female & 220 & 57.60 \\
\hline \multicolumn{3}{|l|}{ Educational level } \\
\hline Diploma & 115 & 30.10 \\
\hline Bachelor & 180 & 47.12 \\
\hline Higher educational degree & 87 & 22.78 \\
\hline \multicolumn{3}{|l|}{ Occupation } \\
\hline Physician & 170 & 44.50 \\
\hline Nurse & 212 & $\mathbf{5 5 . 5 0}$ \\
\hline \multicolumn{3}{|l|}{ Work duration } \\
\hline$<5$ years & 125 & 32.72 \\
\hline $5-10$ years & 165 & 43.19 \\
\hline$>10$ years & 92 & 24.08 \\
\hline \multicolumn{3}{|l|}{ Rotating shifts } \\
\hline Yes & 220 & $\mathbf{5 7 . 5 9}$ \\
\hline No & 162 & 42.41 \\
\hline
\end{tabular}

Bold imphasis indicates the highest frequency

the most negative effect of violence (84.0\%). Most of the staff (64.0\%) told the person to stop violence and avoided violence sources $(40.0 \%)$ as a reaction to violence (Table 2).

Table 3 reveals the most common causes for non-reporting the workplace violence among staff were considering it as non-beneficial (84.8\%), and they did not want it to be recorded in their professional file (75.9\%). The most important contributing factors for violence were high patient expectations (79.1\%) followed by a long waiting period of patients (61.3\%) and intense workload (58.9\%).

Participants' opinions regarding WPV in KGH as illustrated in Graph 1 were as follows: $79.3 \%$ of participants agreed with a prediction of a violent episode by qualified staff, $78.0 \%$ of staff agreed with the responsibility of the patients for all their behavior, and $75.7 \%$ of staff had the right of legal action even when the patient is the abuser. However, some of the staff revealed that the staff pattern and physical setup of work did not protect them $(52.9 \%)$ and staff violated without injury should report the incident (49.7\%), and disagreed that staff who took legal action was at risk of losing their job (49.5\%) consequently.

Regarding the possible preventive measures to control WPV from participants' points of view, security cameras 
Table 2 Workplace violence, types, perpetrators, negative effects, and reaction to it in $\mathrm{KGH}$ during the last six months among the studied participants

\begin{tabular}{|c|c|c|}
\hline WPV during the last 6 months & No. & $\%$ \\
\hline \multicolumn{3}{|l|}{ History of exposure $(\mathrm{n}=382$ ) } \\
\hline Yes & 250 & 65.45 \\
\hline No & 132 & 34.55 \\
\hline \multicolumn{3}{|l|}{ Type of violence: $(n=250)$} \\
\hline Physical & 40 & 16.00 \\
\hline Verbal & 130 & 52.00 \\
\hline Mixed & 80 & 32.00 \\
\hline \multicolumn{3}{|l|}{ Physical violence: $(\mathrm{n}=120)$} \\
\hline Hits & 97 & 80.83 \\
\hline Kicks & 55 & 45.83 \\
\hline Scratches & 33 & 27.5 \\
\hline Pushes & 110 & 91.67 \\
\hline Pinches & 38 & 31.67 \\
\hline \multicolumn{3}{|l|}{ Verbal violence: $(n=210)$} \\
\hline Shouts & 190 & 90.48 \\
\hline Swears & 95 & 45.24 \\
\hline Humiliations & 38 & 18.10 \\
\hline Threats with harm & 123 & 58.57 \\
\hline \multicolumn{3}{|l|}{ Perpetrators of violence: $(n=250)$} \\
\hline Colleagues & 20 & 08.00 \\
\hline Patients & 55 & 22.00 \\
\hline Patient relatives & 220 & 88.00 \\
\hline \multicolumn{3}{|l|}{ Negative effect of violence: $(n=250)$} \\
\hline Physical health & 90 & 36.00 \\
\hline Psychological health & 210 & 84.00 \\
\hline Work performance & 190 & 76.00 \\
\hline Social life & 100 & 40.00 \\
\hline \multicolumn{3}{|l|}{ Reaction to violence: $(\mathrm{n}=250)$} \\
\hline Nothing & 90 & 36.00 \\
\hline Avoid source of violence & 100 & 40.00 \\
\hline Tries to defend themselves physically & 75 & 30.00 \\
\hline Report abuse to manager & 46 & 18.40 \\
\hline Transferred to another position & 73 & 29.20 \\
\hline Tell the person to stop & 160 & 64.00 \\
\hline Use medicine for sleeping & 88 & 35.20 \\
\hline Look for counseling & 75 & 30.00 \\
\hline Avoid thinking or talking about the abuse & 83 & 33.20 \\
\hline Be super alert & 92 & 36.80 \\
\hline Taking sick leave & 85 & 34.00 \\
\hline
\end{tabular}

Bold imphasis indicates the highest frequency

(57.6\%), comfortable waiting rooms (53.7\%), and beefed-up security (49.2\%) were the highest scored measures (Graph 2).

Regarding the relationship between socio-demographic and occupational characteristics of the studied participants and WPV, there were statistically significant associations between young age group ( $<35$ years), sex (males), rotating
Table 3 Reasons for non-reporting and contributing factors for WPV among the studied participants

\begin{tabular}{lll}
\hline Items & No. & $\%$ \\
\hline Reasons for non-reporting: $(\mathrm{n}=204)$ & & \\
Not considered important & 110 & 53.92 \\
No harm intended & 120 & 58.82 \\
Offender apologized & 142 & 69.60 \\
Feel ashamed & 85 & 41.67 \\
Considered not beneficial & 173 & 84.80 \\
Can manage without help & 102 & 50.00 \\
Did not want to it be recorded in their professional file & 155 & 75.98 \\
Others & 2 & 0.98 \\
Contributing factors: $(\mathrm{n}=382)$ & & \\
Intense workload & 225 & 58.90 \\
High patient expectation & 302 & 79.06 \\
Substance abuse by the patient & 210 & 54.97 \\
Long waiting period & 234 & 61.26 \\
Rejection of demands that cannot be accepted & 77 & 20.16 \\
Sensational reports from media & 64 & 16.75 \\
Lack of communication & 98 & 25.65 \\
Inadequate security & 129 & 33.77 \\
Others & 3 & 0.79 \\
\hline
\end{tabular}

shift, duration of work ( $\leq 10$ years), occupation (nurse), educational level (diploma/bachelor), and history of exposure to WPV during the last six months $(\mathrm{p}<0.05)$. Accordingly, multiple logistic regression analysis was conducted. Rotating shift, duration of work ( $\leq 10$ years), young age group $(<35$ years), and sex (males) were the significant predictors for WPV $(\mathrm{p}<0.05)($ Table 4$)$.

\section{Discussion}

Workplace violence against HCWs in conflict settings has been a major concern for decades. The COVID-19 pandemic appended an additional burden on the already stressful healthcare work environment (Said and El-Shafei 2021). The global and rapidly expanding pandemic has placed unprecedented pressures on healthcare systems all over the world. Due to heavy clinical workloads, low clinician-patient ratio, and stressful work settings, HCWs are vulnerable to high risk of WPV (Xie et al. 2021). They have withstood to keep up with the intensifying care needs, and many healthcare structures have suffered enormous difficulties to their provision of healthcare services (Huang et al. 2020).

The current study was conducted in AlKarak Governmental Hospital (KGH) which is a general, governmental hospital dealing with suspected COVID-19 patients 
Graph 1 Participants' opinion regarding WPV in $\mathrm{KGH}$

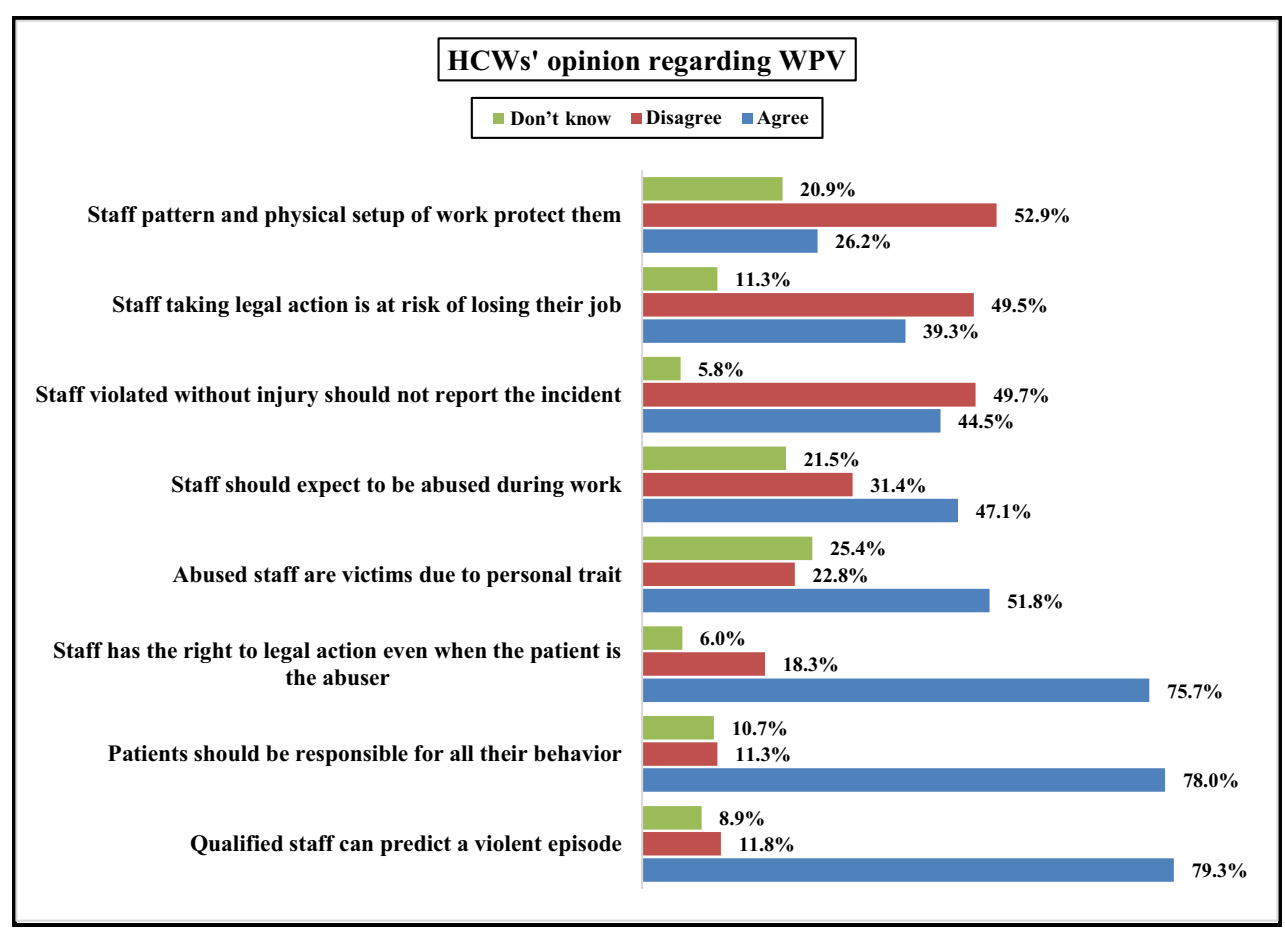

at outpatient clinics or emergency departments and confirmed cases in the isolation section.

Our findings showed a high prevalence of WPV attacks on HCWs $(65.45 \%)$ related to COVID-19. This is higher than that documented by a previous cross-sectional study among Jordanian nurses in different departments at three hospitals in Amman, where the prevalence of verbal and physical abuse was $37.1 \%$ and $18.3 \%$, respectively (Ahmed 2012).
The most elevated rates of physical violence and sexual harassment were found in the European Union, and the highest verbal violence and bullying prevalence were documented in the Middle East (Spector et al. 2014). This was illustrated in the results of our study, where verbal attacks were the most reported WPV attacks among the participants. This is also in line with previous studies in Egypt (AbouElWafa et al. 2015) and Jordan (Oweis and Mousa Diabat
Graph 2 Possible preventive measures to control WPV from participants' points of view

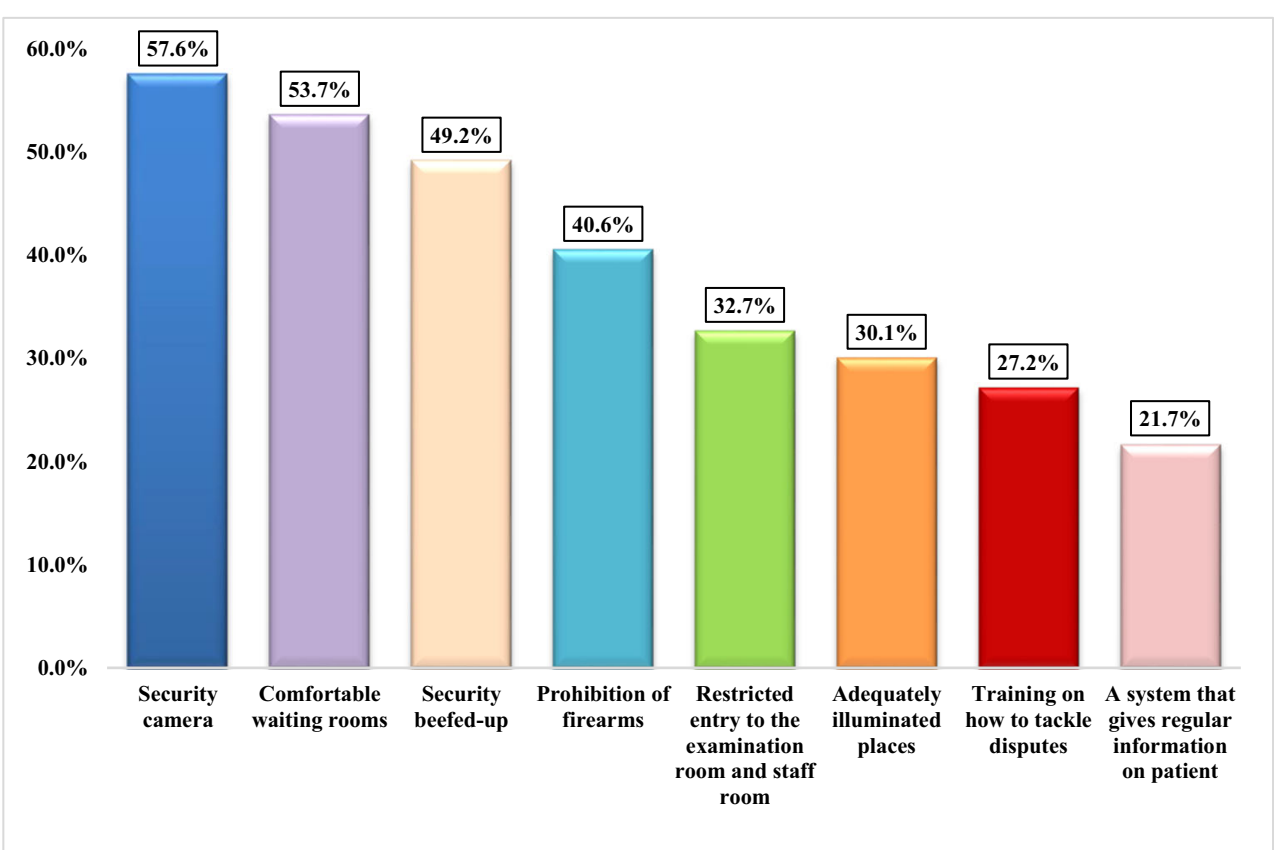


Table 4 Stepwise multiple logistic regression analysis for risk factors of WPV in KGH among the studied participants

\begin{tabular}{ll}
\hline Risk factors of WPV & Adjusted OR (95\% CI) \\
\hline Rotating shift (yes) & $\mathbf{4 . 2}(\mathbf{1 . 9 4 - 7 . 5 8 ) *}$ \\
Duration of work ( $\leq 10$ years) & $\mathbf{3 . 1}(\mathbf{1 . 2 9 - 8 . 6 1 ) *}$ \\
Age group (<35 years) & $\mathbf{2 . 9}(\mathbf{1 . 2 6}-\mathbf{- 7 . 2 2})^{*}$ \\
Male group & $\mathbf{2 . 8}(\mathbf{1 . 5 2 - 8 . 2 3})^{*}$ \\
Nurse group & $1.5(0.75-3.67)$ \\
Educational level (diploma/bachelor) & $1.03(0.44-2.73)$ \\
\hline
\end{tabular}

*Statistically significant $(\mathrm{p}<0.05)$

2005; ALBashtawy 2013), which showed that verbal abuse occurs more often than physical violence. This similarity might be attributed to the fact that the Arab countries almost share culture, social, environmental, and behavioral factors. Moreover, in Ethiopia, verbal abuse was the most wellknown type of violence, followed by physical violence (Fute et al. 2015). In South Korea, a survey study was conducted at a Seoul university hospital and found that the prevalence of verbal abuse was higher than that of physical violence (Park et al. 2015).

On the opposite side, a study done in one of the Palestinian hospitals evidenced a higher prevalence of physical violence $(35.6 \%)$. This might be due to the political issues that raise the stress level that is reflected on patients, their relatives, and HCWs. Also, in Germany, a study was done to evaluate WPV among HCWs in various settings. It was found that about half of participants had experienced physical violence and aggression (Schablon et al. 2012). These previous studies' verities mirror diversified preventive and control measures in each country and patients' relatives' behavior in stressful situations.

In this study, the most prevalent verbal violence types were shouts $(90.48 \%)$ and threats with harm $(58.57 \%)$, while pushes $(91.67 \%)$ and hits $(80.83 \%)$ were the prevalent types of physical violence, and these results agreed with the results documented by Ahmed (2012) where the most predominant type of verbal abuse was shouting and swearing $(75.3 \%$ and $44.5 \%$, respectively), while pushing and hitting were the most common forms of physical violence $(24.4 \%$ and $14.6 \%$, respectively).

The COVID-19 pandemic has generated an extremely threatening environment for HCWs who had reported incidents of violence, discrimination, harassment, and being stigmatized as carriers of infection across many countries. The present study demonstrated that perpetrators of physical and verbal violence were mainly patient relatives, who are often (against regulations) present inside the healthcare facilities during the patient's care. Other studies affirmed the same findings that relatives or friends of the patient mostly were the perpetrators (Erkol et al. 2007; Zafar et al. 2013). According to Spector et al. (2014), the sources of violence differed throughout the world, with patients themselves responsible for majority of it in Anglo-European areas, while the patient's families represent the most frequent threat in the Middle East.

According to a well-established evidence, $\mathrm{HCWs}$ who are subjected to WPV suffer from physical and mental well-being impairment and several other negative consequences that end with more extended periods of absenteeism, work inefficiency, deterioration of work performance, job dissatisfaction, burnout, and high turnover (Cheung and Yip 2017; Sharma et al. 2019).

In accordance with that, our findings showed that the main negative effects of violence were on psychological aspects of HCWs and their work performance. Psychological effects included feeling afraid and worried about people, and worried about talking about the incidents. Moreover, some try to forget, and others always remember the events; all these effects deteriorate mental health, psychological welfare, and wellbeing of the exposed HCWs. These negative mental consequences were also revealed in previous studies (Kowalenko et al. 2005; Ryan et al. 2008; Eker et al. 2012; De Puy et al. 2015). Moreover, the current study revealed that HCWs exposed to violence believed that WPV negatively affected their work quality and may lead to high medical errors and low job satisfaction. This is in accordance with a previous study (Kisa 2008) that illustrated the effect of WPV on the medical attitude HCWs.

The prevalence of WPV in Jordan is a notably prominent problem despite the existing governmental policies and legislations. That may be linked to many problems in the sociocultural and economical contexts that were not valued by the policies (Rayan et al. 2016). Moreover, multiple improper modifications to the law were made that led directly to increased cases of WPV against HCWs in Jordan. An urgent action plan was proposed, but not yet approved (Alhamad et al. 2021).

Controlling WPV necessitates reinforcing and reviving existing policies (Rayan et al. 2016). Accordingly, underreporting is still a prominent issue in our study, that is in accordance with the previous studies across the world (Gerberich et al. 2004; Carmi-Iluz et al. 2005; Gates et al. 2006; Shoghi et al. 2008; El-Gilany et al. 2010; Institute for Emergency Nursing Research 2011; Zafar et al. 2013). The most widely recognized reason for underreporting is the lack of confidence that reporting will benefit the reporters, shyness, and fear of stigma to appear on professional files. Actually, most HCWs do not report violent occurrences believing that reporting does not affect and does not make any difference as WPV is expected and tolerated, especially if they were not exposed to harm. Unfortunately, even some of them believe that experiencing WPV is part of their career. Besides, May 
and Grubbs (2002) found that the significant explanation behind not reporting violent incidents could be the absence of clear hospital policies. On the other hand, Pai and Lee (2011) found that even most registered nurses who reported WPV attacks in Taiwan complained after reporting because no actions or activities were taken.

Regarding the most important contributing factors for WPV against HCWs from participants' point of views, this study observed that the respondents perceive that the high patient expectation, long waiting periods, intense workload, and substance abuse by patients were the important contributing factors. These findings were similar to a previous study in Jordan (Darawad et al. 2015). Also, ALBashtawy (2013) proved that increased waiting time, overcrowding, and high expectations of clients and their families are perceived as significant contributors to enhancing and triggering violent acts. These outcomes were also upheld by different research (Crilly et al. 2004; Mirza et al. 2012).

On the other side, some factors that were the most prominent ones in other studies (Kumar et al. 2016; Imran et al. 2013; Pund et al. 2017; Darawad et al. 2015) were direct contact of HCWs with highly stressed patients and families, unrestricted movements of visitors in the hospitals, overcrowding, lack of staff training in prevention and management of WPV, unsatisfied treatment plan, low staffing level, and predominance of weapons among patients/family members.

By multiple regression analysis, rotating shift, age $<35$ years old, duration of work $\leq 10$ years, and male groups were the most important significant risk factors for WPV among HCWs; this concurs with ALBashtawy (2013) findings who additionally uncovered that attendants who were over 30 years of age and have worked in the emergency department for more than 5 years are exposed to less violence than their co-workers. This can be explained as HCWs who had longer years of work experience and exceeded 30 years old became more professional and mature enough to deal with social events and emergencies and had sufficient communication skills accordingly became more capable of predicting, evaluating, managing, and judging hazardous situations better than younger and less experienced HCWs (Hodgson et al. 2004; Nau et al. 2007; Shoghi et al. 2008). In addition to that, males in this study were at more risk for WPV mainly due to the south regions' cultural issues in Jordon, as they refuse to insult females, and male HCWs usually take night shifts. On the other side, older studies (Nijman et al. 1997; Poster and Ryan 1994) indicated that there was no relationship between years of experience and WPV.

Limitations This study was cross-sectional, so that it is not possible to ascertain a cause-effect relationship; resource constraints limited the study to a single tertiary care hospital, thereby limiting the generalizability of the study. The questionnaire used for data collection relied on the HCWs' memory recall; this may have increased the recall bias.

Conclusion The current study showed that violence against HCWs is a major problem. Verbal violence came first, followed by physical violence. The regular reporting of these incidents is deficient. The victims suffered psychological and physical effects. Also, the study found that the patient's relatives were the principal perpetrators of violence against HCWs. These assaults on healthcare facilities highlight the importance of effective risk communication at all levels of society to minimize anxiety, stigma, and, eventually, WPV. Moreover, the way we communicate about COVID-19 is vital in motivating people to take proactive steps to fight the disease and safeguard healthcare.

Recommendations Prevention is more critical than control. Workplace policies and procedures are needed that focus on the security of the environment, reporting and surveillance, and education for all employees and managers on how to prevent and manage WPV. Educational training programs for HCWs are recommended to effectively focus on communication techniques and stress or conflict resolution to manage WPV, as well as establishing clear procedures for reporting incidents of WPV and encouraging HCWs to report attacks. Annual reviews should be conducted to determine the positive and negative aspects of the established WPV prevention policy.

Acknowledgements The authors would like to thank all participants of this study for their great cooperation.

Author contribution Nanees S. Ghareeb, Dalia A. El-Shafei, and Afaf M. Eladl were responsible for the study and contributed to the study's conception and design. Data collection was performed by Nanees S. Ghareeb. The first draft of the manuscript was written by Nanees S. Ghareeb and Afaf M. Eladl. Critical revision of the manuscript was done by Dalia A. El-Shafei. All of the authors read and approved the final manuscript.

Funding This research did not receive any specific grant from any funding agency in the public, commercial, or not-for-profit sector.

Data availability The datasets used and analyzed during the current study are available from the corresponding author on reasonable request.

\section{Declarations}

Ethics approval The study protocol was approved by the Research Ethics Committee of the Faculty of Medicine, Mutah University. Permission to conduct the study was also secured from the hospital manager. Ethical considerations and confidentiality were respected.

Consent to participate An informed consent was obtained from all participants of this study. The participants were told about the study's aim, and they were informed that the data would be used for scientific purposes 
only. The participants were also given the right to refuse or participate in the study.

\section{Consent for publication Not applicable}

Conflict of interest The authors declare no competing interests.

\section{References}

Abou-ElWafa HS, El-Gilany AH, Abd-El-Raouf SE, Abd-Elmouty SM, El-Sayed R (2015) Workplace violence against emergency versus non-emergency nurses in Mansoura university hospitals, Egypt. J Interpers Violence 30(5):857-872. https://doi.org/10.1177/ 0886260514536278

Ahmed AS (2012) Verbal and physical abuse against Jordanian nurses in the work environment. . Eastern Mediterranean health journal 18(4): 318-324. https://doi.org/10.26719/2012.18.4.318

ALBashtawy M (2013) Workplace violence against nurses in emergency departments in Jordan. Int Nurs Rev 60(4):550-555. https://doi.org/ 10.1111/inr.12059

Alhamad, R., Suleiman, A., Bsisu, I., Santarisi, A., Al Owaidat, A., Sabri, A., Farraj, M., Al Omar, M., Almazaydeh, R., Odeh, G., Al Mousa, M., \& Mahseeri, M. (2021). Violence against physicians in Jordan: an analytical cross-sectional study. PLoS One, 16(1), \. https://doi. org/10.1371/journal.pone.0245192

Alsaleem SA, Alsabaani A, Alamri RS, Hadi RA, Alkhayri MH, Badawi KK, Badawi AG, Alshehri AA, Al-Bishi AM (2018) Violence towards healthcare workers: a study conducted in Abha City, Saudi Arabia. J Fam Community Med 25(3):188-193. https://doi.org/10. 4103/jfcm.JFCM_170_17

Carmi-Iluz T, Pelag R, Freud T et al (2005) Verbal and physical violence towards hospital- and community-based physicians in the Neger: an observational study. BMC Health Serv Res 5:54-59

Cheung T, Yip P (2017) Workplace violence towards nurses in Hong Kong: prevalence and correlates. BMC Public Health 17(1):196. https://doi.org/10.1186/s12889-017-4112-3

Crilly J, Chaboyer W, Creedy D (2004) Violence towards emergency department nurses by patients. Accid Emerg Nurs 12(2):67-73. https://doi.org/10.1016/j.aaen.2003.11.003

Darawad MW, Al-Hussami M, Saleh AM, Mustafa WM, Odeh H (2015) Violence against nurses in emergency departments in Jordan: nurses' perspective. Worke health saf 63(1):9-17. https://doi.org/ 10.1177/2165079914565348

De Puy J, Romain-Glassey N, Gut M, Wild P, Mangin P, Danuser B (2015) Clinically assessed consequences of workplace physical violence. Int Arch Occup Environ Health 88(2):213-224. https://doi. org/10.1007/s00420-014-0950-9

Devi S (2020) COVID-19 exacerbates violence against health workers. Lancet (London, England) 396(10252):658. https://doi.org/10.1016/ S0140-6736(20)31858-4

Eker H, Özder A, Tokaç M et al (2012) Aggression and violence towards health care providers, and effects thereof. Arch Psychiatry Psychother 4:19-29

El-Gilany A, El-Wehady A, Amr M (2010) Violence against primary health care workers in Al-Hassa, Saudi Arabia. J Interpers Violence 25(4):716-734

Erkol H, Gökdoğan MR, Erkol Z, Boz B (2007) Aggression and violence towards health care providers-a problem in Turkey? J Forensic Legal Med 14(7):423-428. https://doi.org/10.1016/j.jflm.2007.03. 004

Fallahi-Khoshknab M, Oskouie F, Najafi F, Ghazanfari N, Tamizi Z, Afshani S (2016) Physical violence against health care workers: a nationwide study from Iran. Iran J Nurs Midwifery Res 21(3):232238. https://doi.org/10.4103/1735-9066.180387

Ferri P, Silvestri M, Artoni C, Di Lorenzo R (2016) Workplace violence in different settings and among various health professionals in an Italian general hospital: a cross-sectional study. Psychol Res Behav Manag 9:263-275. https://doi.org/10.2147/PRBM.S114870

Fute M, Mengesha ZB, Wakgari N, Tessema GA (2015) High prevalence of workplace violence among nurses working at public health facilities in Southern Ethiopia. BMC Nurs 14:9. https://doi.org/10.1186/ s12912-015-0062-1

Gates DM, Ross CS, McQueen L (2006) Violence against emergency department workers. J Emerg Med 31(3):331-337. https://doi.org/ 10.1016/j.jemermed.2005.12.028

Gerberich SG, Church TR, McGovern PM, Hansen HE, Nachreiner NM, Geisser MS, Ryan AD, Mongin SJ, Watt GD (2004) An epidemiological study of the magnitude and consequences of work related violence: the Minnesota Nurses' Study. Occup Environ Med 61(6): 495-503. https://doi.org/10.1136/oem.2003.007294

Harthi M, Olayan M, Abugad H, Abdel Wahab M (2020) Workplace violence among healthcare workers in emergency departments of public hospitals in Dammam, Saudi Arabia. East Mediterr Health J 26(12):1473-1481. https://doi.org/10.26719/emhj.20.069

Hodgson MJ, Reed R, Craig T, Murphy F, Lehmann L, Belton L, Warren $\mathrm{N}$ (2004) Violence in healthcare facilities: lessons from the Veterans Health Administration. J Occup Environ Med 46(11):1158-1165. https://doi.org/10.1097/01.jom.0000141658.91805.47

Huang JZ, Han MF, Luo TD, Ren AK, Zhou XP (2020) Zhonghua lao dong wei sheng zhi ye bing za $\mathrm{zhi}=$ Zhonghua laodong weisheng zhiyebing zazhi $=$ Chinese journal of industrial hygiene and occupational diseases. 38(3):192-195. https://doi.org/10.3760/cma.j. cn121094-20200219-00063

Imran N, Pervez M, Farooq R et al (2013) Aggression and violence towards medical doctors and nurses in: a public health care facility in Lahore, Pakistan: a preliminary investigation. Khyber Med Univ J 5:4 https://www.kmuj.kmu.edu.pk/article/view/11811 Accessed 6 Mar 2021

Institute for Emergency Nursing Research (2011) Emergency department violence surveillance study, November: Emergency Nurses Association. Available at http://www.ena.org/IENR/Documents/ ENAEDVSReportNovember2011.Pdf. Accessed 6 Mar 2021

Khan MN, Haq ZU, Khan M, Wali S, Baddia F, Rasul S, Khan S, Polkowski M, Ramirez-Mendoza JY (2021) Prevalence and determinants of violence against health care in the metropolitan city of Peshawar: a cross sectional study. BMC Public Health 21:330. https://doi.org/10.1186/s12889-021-10243-8

Kisa S (2008) Turkish nurses' experiences of verbal abuse at work. Arch Psychiatr Nurs 22(4):200-207. https://doi.org/10.1016/j.apnu.2007. 06.013

Kowalenko T, Walters BL, Khare RK, Compton S, Michigan College of Emergency Physicians Workplace Violence Task Force (2005) Workplace violence: a survey of emergency physicians in the state of Michigan. Ann Emerg Med 46(2):142-147. https://doi.org/10. 1016/j.annemergmed.2004.10.010

Kumar M, Verma M, Das T, Pardeshi G, Kishore J, Padmanandan A (2016) A study of workplace violence experienced by doctors and associated risk factors in a tertiary care hospital of South Delhi, India. J Clin Diagn Res : JCDR 10(11):LC06-LC10. https://doi. org $/ 10.7860 / \mathrm{JCDR} / 2016 / 22306.8895$

May DD, Grubbs LM (2002) The extent, nature, and precipitating factors of nurse assault among three groups of registered nurses in a regional medical center. J Emerg Nurs 28(1):11-17. https://doi.org/10. 1067/men.2002.121835

Mirza NM, Amjad AI, Bhatti AB, Tuz Zahra Mirza F, Shaikh KS, Kiani J, Yusuf MM, Khan MU, Nazir ME, Assad Q, Humayun A, Kiani IG, Amjad SI, Imam SZ (2012) Violence and abuse faced by junior physicians in the emergency department from patients and their 
caretakers: a nationwide study from Pakistan. J Emerg Med 42(6): 727-733. https://doi.org/10.1016/j.jemermed.2011.01.029

Mishra S, Chopra D, Jauhari N, Ahmad A, Kidwai NA (2018) Violence against healthcare workers: a provider's (staff nurse) perspective. Int J Community Med Public Health 5(9):4140-4148. https://doi.org/ 10.18203/2394-6040.ijcmph20183609

Nau J, Dassen T, Halfens R, Needham I (2007) Nursing students' experiences in managing patient aggression. Nurse Educ Today 27(8): 933-946. https://doi.org/10.1016/j.nedt.2007.01.007

Neto M, Almeida HG, Esmeraldo JD, Nobre CB, Pinheiro WR, de Oliveira C, Sousa I, Lima O, Lima N, Moreira MM, Lima C, Júnior JG, da Silva C (2020) When health professionals look death in the eye: the mental health of professionals who deal daily with the 2019 coronavirus outbreak. Psychiatry Res. Advance online publication 288:112972. https://doi.org/10.1016/j.psychres.2020.112972

Nijman HL, Merckelbach HL, Allertz WF, Campo J Ma (1997) Prevention of aggressive incidents on a closed psychiatric ward. Psychiatr Serv (Washington, DC) 48(5):694-698. https://doi.org/ $10.1176 /$ ps.48.5.694

Oweis A, Mousa Diabat K (2005) Jordanian nurses perception of physicians' verbal abuse: findings from a questionnaire survey. Int J Nurs Stud 42(8):881-888. https://doi.org/10.1016/j.ijnurstu.2004.11.005

Pai HC, Lee S (2011) Risk factors for workplace violence in clinical registered nurses in Taiwan. J Clin Nurs 20(9-10):1405-1412. https://doi.org/10.1111/j.1365-2702.2010.03650.x

Park M, Cho SH, Hong HJ (2015) Prevalence and perpetrators of workplace violence by nursing unit and the relationship between violence and the perceived work environment. J Nurs Scholarsh 47(1):87-95. https://doi.org/10.1111/jnu.12112

Poster EC, Ryan J (1994) A multiregional study of nurses' beliefs and attitudes about work safety and patient assault. Hosp Community Psychiatry 45(11):1104-1108. https://doi.org/10.1176/ps.45.11. 1104

Pund S, Kuril B, Doibale M et al (2017) Study of workplace violence, its risk factors and perceptions about workplace security in doctors of Paithan. Int J Community Med Public Health 4:1987-1992. https:// doi.org/10.18203/2394-6040.ijcmph20172162

Rayan A, Qurneh A, Elayyan R, Baker O (2016) Developing a policy for workplace violence against nurses and health care professionals in Jordan: a plan of action. Am J Public Health Res 4(2):47-55. https:// doi.org/10.12691/ajphr-4-2-2

Rodríguez-Bolaños R, Cartujano-Barrera F, Cartujano B, Flores YN, Cupertino AP, Gallegos-Carrillo K (2020) The urgent need to address violence against health workers during the COVID-19 pandemic. Med Care 58(7):663. https://doi.org/10.1097/MLR. 0000000000001365

Ryan EP, Aaron J, Burnette ML, Warren J, Burket R, Aaron T (2008) Emotional responses of staff to assault in a pediatric state hospital. $\mathrm{J}$ Am Acad Psychiatry Law 36(3):360-368
Said RM, El-Shafei DA (2021) Occupational stress, job satisfaction, and intent to leave: nurses working on front lines during COVID-19 pandemic in Zagazig City, Egypt. Environ Sci Pollut Res Int 28(7):8791-8801. https://doi.org/10.1007/s11356-020-11235-8

Schablon A, Zeh A, Wendeler D, Peters C, Wohlert C, Harling M, Nienhaus A (2012) Frequency and consequences of violence and aggression towards employees in the German healthcare and welfare system: a cross-sectional study. BMJ Open 2:e001420. https://doi. org/10.1136/bmjopen-2012-001420

Sharma S, Lal Gautam P, Sharma S, Kaur A, Bhatia N, Singh G, Kaur P, Kumar A (2019) Questionnaire-based evaluation of factors leading to patient-physician distrust and violence against healthcare workers. Indian journal of critical care medicine : peer-reviewed, official publication of Indian Society of Critical Care Medicine 23(7):302-309. https://doi.org/10.5005/jp-journals-10071-23203

Sharma A, Tiwari S, Deb MK, Marty JL (2020) Severe acute respiratory syndrome coronavirus-2 (SARS-CoV-2): a global pandemic and treatment strategies. Int J Antimicrob Agents 56(2):106054. https://doi.org/10.1016/j.ijantimicag.2020.106054

Shoghi M, Sanjari M, Shirazi F, Heidari S, Salemi S, Mirzabeigi G (2008) Workplace violence and abuse against nurses in hospitals in iran. Asian Nurs Res 2(3):184-193. https://doi.org/10.1016/S19761317(08)60042-0

Spector PE, Zhou ZE, Che XX (2014) Nurse exposure to physical and nonphysical violence, bullying, and sexual harassment: a quantitative review. Int J Nurs Stud 51(1):72-84. https://doi.org/10.1016/j. ijnurstu.2013.01.010

World health organization (WHO) (2018) Violence against health workers. Available at http://www.who.int/violence injury prevention/violence/workplace/en/ (last cited on 22nd October 2018)

Xie XM, Zhao YJ, An FR, Zhang QE, Yu HY, Yuan Z, Cheung T, Ng $\mathrm{CH}$, Xiang YT (2021) Workplace violence and its association with quality of life among mental health professionals in China during the COVID-19 pandemic. J Psychiatr Res 135:289-293. https://doi.org/ 10.1016/j.jpsychires.2021.01.023

Yenealem DG, Woldegebriel MK, Olana AT, Mekonnen TH (2019) Violence at work: determinants \& prevalence among health care workers, northwest Ethiopia: an institutional based cross sectional study. Ann Occup Environ Med 31:8. https://doi.org/10.1186/ s40557-019-0288-6

Zafar W, Siddiqui E, Ejaz K, Shehzad MU, Khan UR, Jamali S, Razzak JA (2013) Health care personnel and workplace violence in the emergency departments of a volatile metropolis: results from Karachi, Pakistan. J Emerg Med 45(5):761-772. https://doi.org/10. 1016/j.jemermed.2013.04.049

Publisher's note Springer Nature remains neutral with regard to jurisdictional claims in published maps and institutional affiliations. 